\title{
Chapter 3 \\ Exploring the Cohabitation Gap in Relationship Dissolution and Health and Wellbeing: A Longitudinal Analysis of Transitions from Cohabitation and Marriage in Switzerland and Australia
}

\author{
Belinda Hewitt, Marieke Voorpostel, and Gavin Turrell
}

\section{Introduction}

A long line of research has found that being married improves health and wellbeing and that marital dissolution negatively impacts health and wellbeing (Gove and Shin 1989; Umberson et al. 2010). Yet, the institution of marriage as the bedrock of family life has declined over the last few decades. Across developed countries, divorce rates remain relatively high and unmarried cohabitation as an alternative or prelude to marriage has increased (Cherlin 2009; Kiernan 2002). The rise of cohabitation as an alternative to marriage raises questions about whether marriage confers greater benefits to health and wellbeing over cohabitation (Musick and Bumpass 2012), which also has implications for the health consequences of relationship dissolution following cohabitation and marriage. Cohabitation may provide many of the same resources as marriage in terms of social support, integration, economies of scale, and lifestyle habits and behaviours, although this may partly depend on the stability and degree of commitment in the cohabiting relationship (Seltzer 2000). Overall,

\footnotetext{
B. Hewitt $(\bowtie)$

School of Social and Political Sciences, The University of Melbourne,

Parkville, VIC, Australia

e-mail: belinda.hewitt@unimelb.edu.au

M. Voorpostel

FORS-Swiss Centre of Expertise in the Social Sciences, Lausanne, Switzerland

e-mail: Marieke.voorpostel@fors.unil.ch

G. Turrell

School of Health and Social Development, Deakin University,

Melbourne, VIC, Australia

e-mail: gavin.turrell@acu.edu.au

(c) The Author(s) 2018

R. Tillmann et al. (eds.), Social Dynamics in Swiss Society, Life Course

Research and Social Policies 9, https://doi.org/10.1007/978-3-319-89557-4_3
}

31 
cohabiting relationships tend to be less stable than marriage (Wiik et al. 2012; Hewitt and Baxter 2015). While a relatively large number of studies examine health differences between married and cohabiting people when they form relationships, much less attention has been paid to comparing the health impacts of relationship dissolution. In this chapter we examine gendered health differences in relationship dissolution, using longitudinal panel data from the Swiss Household Panel Study and the Household, Income and Labour Dynamics in Australia study, enabling a comparison between Switzerland and Australia, two countries that differ in health policy and outcomes as well as in relationship trajectories.

\section{Background}

\section{Previous Findings on Union Dissolution and Health}

Research consistently shows that married men and women have lower mortality rates and better psychological and physical wellbeing compared with unmarried individuals, and that health and wellbeing decline after divorce (Hewitt et al. 2011; Williams and Umberson 2004). Comparing previously married to married individuals, Hughes and Waite (2009) found that the previously married had worse physical and mental health. However, in their meta-analysis, Luhmann et al. (2012) found little effect of the legal act of divorce itself on positive and negative feelings, but were not able to look at the period preceding the divorce, in which wellbeing may already have declined.

The majority of studies that compare health in cohabiting and married couples have concentrated on health differences as individuals move into or remain in their relationships. The findings of these studies are mixed, but often no differences are found in physical and mental health (Wu et al. 2003; Horowitz and White 1998) or mortality (Lund et al. 2002) of cohabiting versus married people. Gender is at the centre of the debate about the health and wellbeing benefits of marriage. While both men and women have been found to benefit from marriage, on average men have been found to benefit more than women (Williams and Umberson 2004). Some studies on cohabitation show that cohabiting men have better health than women (Aassve et al. 2007).

Few studies have investigated what happens to health when cohabiting and marital relationships end and here the evidence is mixed as well. In a Canadian study, Wu et al. (2003) found no differences in the health consequences of separation for married and cohabiting couples. Other research using data from Britain (Blekesaune 2008) and Australia (Hewitt and Baxter 2015) suggests that the health consequences of relationship dissolution may not be as severe for cohabitants compared to married people. 


\section{Union Dissolution and Health: Why Would Cohabitation Be Different from Marriage?}

The divorce literature proposes three mechanisms through which union dissolution affects health and wellbeing: a decrease in resources, a decrease in social support and separation as a stressful event (Johnson and Wu 2002). First, union dissolution tends to be accompanied by a decrease in economic resources (Aassve et al. 2007), which in turn has negative consequences for health and wellbeing through increased stress, cutting back spending on healthcare and a healthy life style and poorer housing. As couples separate, they lose economies of scale and may face additional costs. Whereas this applies to both married and cohabiting couples, the effects may be weaker for cohabiting couples as they are less likely to have shared bank accounts (Hiekel et al. 2014) or shared home ownership (Mulder and Wagner 2001).

The effect of separation on health and wellbeing may be stronger for women as they tend to experience a larger decrease in economic resources after divorce compared with men, mainly due to the fact that they have weaker attachment to the labour market and tend to be responsible for children (Bianchi et al. 1999). This gender difference may be smaller for separation from cohabitation, because in cohabiting relationships women tend to contribute a higher proportion of household income, and therefore tend to be less dependent on their partners (Kalmijn et al. 2007; Hewitt and Baxter 2015). In addition, cohabiting women are less likely to have responsibility for dependent children after relationship dissolution as cohabitors are less likely to have shared children than those who are married (Hewitt et al. 2010). Together this suggests that married women may lose the most economic resources after relationship dissolution and therefore have poorer health.

Second, union dissolution may affect health through changes in social networks and reduced social support. Marriage provides social support, social integration, love and companionship, as well as social status through entry into a recognised, socially and legally-supported institution (Gove and Shin 1989). There may be little or no difference between marriage and cohabitation for health because many of the social support benefits to marriage accrue to cohabitation, although it lacks the symbolic commitment and secure legal institutional status that comes from marriage. In terms of broader social networks, however, those in cohabiting relationships have been found to have smaller social networks than married people (Nock 1995). Also, cohabiting couples tend to have more independent social lives compared with married couples (Kalmijn and Bernasco 2001), which means that their social networks might be less affected by partnership dissolution. Changes to the social network upon divorce appear to be especially strong for men, whereas women may even benefit as they tend to increase their social networks following divorce (Kalmijn and Broese van Groenou 2005).

Finally, relationship dissolution may affect health because it is a stressful event in itself, even if it was desired, and may be accompanied by additional stressors, such as raising a child alone, a strained relationship with the former spouse, and possibly social stigma (Amato 2000). As cohabiting couples typically have been together less 
time, are less financially dependent on each other, less likely to have children (although there is an increase in births in cohabiting relationships), or to have joint bank accounts and homes, we might expect that separating from cohabitation may be logistically easier than marriage, and hence less detrimental to health and wellbeing. In addition, cohabiting couples tend to have less interpersonal commitment to their relationship, higher expectations that the relationship will end (Wiik et al. 2012) and lower levels of relationship quality and satisfaction (Brown 2003).

Together, the evidence on differences between cohabiting and married couples suggests that the economic, social and emotional costs of ending cohabiting relationships are lower than marriages, we therefore might expect that the health effects for ending a cohabiting relationship will be less severe.

\section{Health Selection and Cohabitation}

These arguments so far assume that being married or in a cohabiting relationship produces certain health outcomes. In addition to arguments that separation may negatively affect health, it is important to note that the causality may also go in the other direction. With regard to relationship dissolution the selection argument asserts that individuals in poorer health are more likely to separate, because poor health is associated with less a favourable economic situation, which may put more strain on the relationship. Overall, this reversed causality has received a lot less attention in the literature. The few studies that test both selection and causal processes find evidence for both processes (Monden and Uunk 2013; Johnson and Wu 2002). However, none of these previous studies consider cohabitation and marriage. Much of the prior research comparing health differences between cohabitors and married people has been cross-sectional comparing groups at a single point in time. Selection, causation and the health impact of transitions cannot be evaluated using cross-sectional data, because they do not enable pre-existing health and well-being to be accounted for (Johnson and Wu 2002).

\section{This Study}

We build on previous literature in several ways. By examining differences in health consequences of relationship dissolution between cohabitors and married couples, we contribute to a relatively understudied area. We further advance our understanding of the health effects of relationship dissolution by examining the short-term health outcomes when an individual transitions out of a marital or cohabiting relationship (Blekesaune 2008). We examine a range of health outcomes that capture changes in wellbeing with relationship dissolution including global health, and measures of negative and positive feelings. Finally, we compare and contrast experiences across two countries, Switzerland and Australia. These two countries offer an interesting comparison for two reasons. First, they differ in terms of their health 
policy, expenditure on health care and the overall health outcomes in each country. On average Switzerland enjoys higher levels of overall health, but spends less on health care (Shi 1997). In addition, the two countries have different marital and cohabiting trajectories. In Switzerland, cohabitations tend to be shorter in duration than in Australia and more likely to end in marriage rather than separation than in Australia (de Vaus 2004; Heuveline and Timberlake 2005). This suggests that cohabitation as a longer term alternative to marriage is less likely in Switzerland, which would suggest that separation from cohabiting relationships may have smaller health consequences in that country. Alternatively, the Swiss may also be less likely to enter into less serious cohabiting relationships, which indicates that there may be more severe consequences on average for them. By undertaking this comparison, this study will offer some interesting insights into the dynamics of different health policy and normative relationship contexts in shaping health outcomes.

\section{Methods}

\section{Data}

To examine the dynamics of health, marriage and cohabitation between Australia and Switzerland we use longitudinal data from the Household, Income and Labour Dynamics in Australia (HILDA) and the Swiss Household Panel (SHP). The panels are relatively well suited for comparison. They have been running about the same amount of time, HILDA began in 2000 and SHP in 1999, and have many design features in common. Most importantly, these longitudinal surveys that broadly cover similar topics, allow us to follow the same individuals over time as they move through different relationship statuses.

\section{Dependent Variables}

The SHP and the HILDA have a number of similar, although not identical, health and wellbeing measures. We examine three outcomes that capture overall health, negative and positive feelings. The first is a self-reported measure of general health. The question for SHP asks, Talking about your health, how do you feel right now? With responses on a 5 point scale including: "very well", "well", "so, so (average)", "not very well", to "not well at all". The question for HILDA asks, In general, would you say your health is? With responses ranging from "excellent" to "poor" on a 5 point scale. A higher score indicates poorer overall health. Self-reported health measures based on a single question are used extensively in epidemiological and general social surveys, and research has shown that they are a valid and reliable indicator of health status encompassing both psychosocial and biological aspects of health (Burstrom and Fredlund 2001; Martikainen et al. 1999). Moreover selfreported health is a valid indicator of objectively assessed adverse psychosocial and 
physiological morbidity, and is a strong and consistent predictor of mortality (Burstrom and Fredlund 2001). We also develop an indicator of negative feelings. There are no exactly matching measures. For the SHP the question asked was: Do you often have negative feelings such as having the blues, being desperate, suffering from anxiety or depression, if 0 means "never" and 10 "always"? For inclusion in the models this was scaled to range from 0-5. For HILDA, we used 3 questions: How much of the time in the past 4 weeks: Have you been a nervous person + Have you felt so down in the dumps that nothing could cheer you up + Have you felt down. Answers ranged from "all of the time" to "none of the time". These scores were reversed and then summed together and divided by 3 to get a scale ranging from $0-5$. A higher score for both measures reflects more frequent negative feelings. Our third indicator captures positive feelings. The SHP measure the question asked: Are you often plenty of strength, energy and optimism, if 0 means "never" and 10 "always"? The HILDA measure combined 2 questions, How much of the time during the past 4 weeks: Did you feel full of life? + Did you have a lot of energy? Answers ranged from "all of the time" to "none of the time". These scores were summed together. Both scales ranged from 0 to 10 , with a higher score reflecting more frequent positive feelings.

\section{Key Independent Variable: Relationship Status and Relationship Dissolution}

Our main independent measure of interest was relationship status. Each study identified people who were married, cohabiting, separated, divorced, widowed or never married. Because we are interested in relationship dissolution due to separation and divorce we exclude those who become widowed from our analyses. In addition, due to the relatively low numbers of those becoming either separated or divorced (see Table 3.1), we collapse them into one group. To take advantage of the longitudinal nature of the data we differentiated between those who remained stable in their relationship, either married or cohabiting between waves from those who became separated or divorced between waves. This enabled us to capture any changes in health and well-being in the lead up to relationship dissolution. Our final measure differentiated: married, married-transition (to become separated/divorced in the next wave), cohabiting, cohabiting-transition (to become separated/divorced/never married in the next wave), separated/divorced, or never married.

\section{Controls}

We want to assess health and wellbeing differences between marital dissolution and dissolution of a cohabiting relationship net of characteristics in which the two groups differ that are also associated with health. Cohabiting men tend to have lower levels of employment and earnings than married men (Xie et al. 2003; Kalmijn 
Table 3.1 Descriptive statistics of dependent variables and controls for pooled sample, by men and women, Australia (14 waves HILDA) and Switzerland (16 waves SHP)

\begin{tabular}{|c|c|c|c|c|}
\hline & \multicolumn{2}{|l|}{ Australia } & \multicolumn{2}{|l|}{ Switzerland } \\
\hline & Men & Women & Men & Women \\
\hline & Mean $(\mathrm{SD}) / \%^{\mathrm{a}}$ & Mean(SD)/\% & Mean $(\mathrm{SD}) / \%$ & Mean(SD)/\% \\
\hline \multicolumn{5}{|l|}{ Health measures: } \\
\hline $\begin{array}{l}\text { Self-reported general health } \\
(1-5)\end{array}$ & $3.43(0.9)$ & $3.48(0.9)$ & $4.10(0.6)$ & $4.05(0.7)$ \\
\hline Negative feelings $(0-5)$ & $0.84(0.8)$ & $0.96(0.9)$ & $0.81(0.9)$ & $1.09(1.0)$ \\
\hline Positive feelings $(0-10)$ & $6.07(2.1)$ & $5.78(2.2)$ & $7.44(1.7)$ & $7.32(1.7)$ \\
\hline \multicolumn{5}{|l|}{ Children: } \\
\hline No dependent child $<18$ (ref) & 55 & 51 & 52 & 53 \\
\hline Dependent child $<18$ & 45 & 49 & 48 & 47 \\
\hline \multicolumn{5}{|l|}{ Employment status: } \\
\hline $\begin{array}{l}\text { Working fulltime, } 90-100 \% \\
\text { (ref) }\end{array}$ & 77 & 36 & 79 & 20 \\
\hline Working part-time, $1-89 \%$ & 9 & 55 & 13 & 41 \\
\hline Unemployed & 3 & 3 & 1 & 2 \\
\hline Inactive & 11 & 29 & 7 & 23 \\
\hline \multicolumn{5}{|l|}{ Education: } \\
\hline Basic schooling (ref) & 22 & 31 & 5 & 15 \\
\hline Secondary schooling & 52 & 42 & 45 & 60 \\
\hline Tertiary schooling & 26 & 28 & 50 & 25 \\
\hline \multicolumn{5}{|l|}{ Household (HH) income (quartiles) $)^{\text {b: }}$} \\
\hline $\begin{array}{l}<25 \% \text { HH income } \\
\text { (1st quartile) (ref) }\end{array}$ & 24 & 26 & 21 & 27 \\
\hline $\begin{array}{l}25 \%-50 \% \mathrm{HH} \text { income } \\
\text { (2nd quartile) }\end{array}$ & 25 & 25 & 25 & 25 \\
\hline $\begin{array}{l}50 \%-75 \% \mathrm{HH} \text { income } \\
\text { (3rd quartile) }\end{array}$ & 26 & 25 & 27 & 24 \\
\hline $75 \%+\mathrm{HH}$ income (4th quartile) & 26 & 25 & 27 & 24 \\
\hline Person observations & 55,162 & 60,195 & 25,775 & 31,268 \\
\hline
\end{tabular}

${ }^{a}$ Mean and SD reported for continuous measures and \% reported for categorical measures

${ }^{b}$ Household income quartiles were calculated on total household income both countries. The overall \% of men and women each country vary due to women's increase likelihood of being in lower income households in both countries

et al. 2007), which may in turn improve the wellbeing of both partners. In part the better wellbeing of married people compared with those cohabiting is partly explained by differences in material resources (Soons and Kalmijn 2009). In our models we controlled for: age in years (centred around the mean), employment status (working 90-100\%, working 1-89\%, unemployed, inactive), level of education (primary, secondary, tertiary level of education), household income in quartiles, whether or not there is a child under 18 years old in the household, and whether the household owns or rents the home. Descriptive statistics for dependent variables and controls are presented in Table 3.1. 


\section{Analytic Approach}

We estimated a series of fixed effects regression models for each dependent variable. In each case the dependent variable is treated continuously. To exploit the longitudinal nature of the data and to best capture the effect of relationship dissolution on health and wellbeing, we also included a 1-year lag for marital status, where the reference group were those participants stably married between waves. The inclusion of this lagged marital status measure enabled us to estimate the effect of transitions from married or cohabiting in the previous wave $\left(\mathrm{t}_{-1}\right)$ to being separated/ divorced (t) on health and wellbeing in the current wave, compared to those who were stably married or cohabiting between waves. Assessing time varying covariates in this way allowed us to determine the extent to which within-person variation in a relationship status was associated with within person variation on the health outcomes. Because interpretation is not straight forward in that both the lagged and main effect for relationship status need to be taken into account, we present our results graphically showing the predicted change in health for respondents whose relationships ended compared to those who remained married or cohabiting that includes the main and lagged effect for relationship status. It should also be noted that the use of lagged predictors requires that respondents have complete data for at least 2 points in time, therefore our lagged analysis used wave 2 as the baseline observation point (Shaw and Liang 2012).

Analysis proceeded in two stages. First, we estimated a baseline model (Model 1) which included relationship status, relationship status in the previous wave and age. Second, we included the controls to Model 1 (Model 2). While there were changes in the magnitude of coefficients with Model 2, there were few changes in the overall significance and substantive interpretation of the results and we only present the results of the second model.

\section{Results}

\section{Relationship Transitions}

Table 3.2 shows how the respondents transition between relationship states from wave-to-wave. Switzerland and Australia are more similar than different with regard to relationship dissolution patterns. The most stable group were the married individuals; in more than $98 \%$ of observations respondents were married in both waves. We observe that about $1.69 \%$ of the HILDA sample and $0.73 \%$ of the SHP sample transition from married to separated between waves, and $0.10 \%$ and $0.18 \%$ transitioning from married to divorced. As indicated earlier we collapsed the separated and divorced in our analyses. As expected cohabiting relationships were much less stable than marriage. Around $81 \%$ of cohabiting individuals in both countries remained stably cohabiting between waves, $6.41 \%$ transition to never married in 
Table 3.2 Separation and divorce transitions from cohabitation and marriage in Switzerland and Australia in percentages

\begin{tabular}{l|l|l|l|l|l|l}
\hline \multirow{3}{*}{$\begin{array}{l}\text { Relationship } \\
\text { status (t-1) }\end{array}$} & Country & Married & Cohabiting & Separated & Divorced & $\begin{array}{l}\text { Never } \\
\text { Married }\end{array}$ \\
\cline { 2 - 7 } Married & Australia & 98.05 & 0.16 & 1.69 & 0.10 & 0 \\
\cline { 2 - 7 } & Switzerland & 98.91 & 0.18 & 0.73 & 0.18 & 0 \\
\hline \multirow{2}{*}{ Cohabiting } & Australia & 10.94 & 80.62 & 0.39 & 1.65 & 6.41 \\
\cline { 2 - 8 } & Switzerland & 10.26 & 81.89 & 0.40 & 1.87 & 5.59 \\
\hline \multirow{2}{*}{ Separated } & Australia & 6.64 & 9.72 & 63.22 & 20.42 & 0 \\
\cline { 2 - 8 } & Switzerland & 3.59 & 6.03 & 65.85 & 24.52 & 0 \\
\hline \multirow{2}{*}{ Divorced } & Australia & 3.19 & 10.73 & 1.42 & 84.66 & 0 \\
\cline { 2 - 8 } & Switzerland & 1.44 & 6.78 & 0.22 & 91.56 & 0 \\
\hline \multirow{2}{*}{ Never Married } & Australia & 1.66 & 15.65 & 0 & 0 & 82.58 \\
\cline { 2 - 7 } & Switzerland & 2.80 & 15.66 & 0 & 0 & 81.55 \\
\hline
\end{tabular}

Australia and $5.59 \%$ transition to never married in Switzerland. A relatively large proportion of cohabitors also transitioned to divorced 1.65\% in Australia and 1.87\% in Switzerland. Overall, we find that Swiss relationships, both marriage and cohabitation, tend to be more stable than Australian relationships.

Next we discuss the results of the models, while there are a large number of possible transitions we could focus on (as shown in Table 3.2), we concentrate on the most common transitions, from married to separated/divorced and from cohabiting to never married.

\section{Self-Rated Health}

Our results for self-rated health are presented in Fig. 3.1, based on the results in the first two columns of Appendix Table A.1. Among Australian men there was no indication that separation from cohabitation or marriage has a negativse effect on SRH. Although Graph 1a shows an increase in self-rated health following separation from cohabitation, this effect is not significant. Australian women (Graph 1c), however, show a significant lower level of SRH the year prior to separation from cohabitation. No comparable effect was found for separation from marriage. Although the figures of the Swiss sample (Graphs 1b and 1d) show a decrease in SRH in the year of separation from marriage, these effects were only significant in the lagged effect for Swiss women. For SRH we did not find the expected negative association with relationship dissolution, neither did we find support for the idea that this effect would be different for separation from marriage and stronger in Switzerland compared with Australia. 
(1a) Australian Men

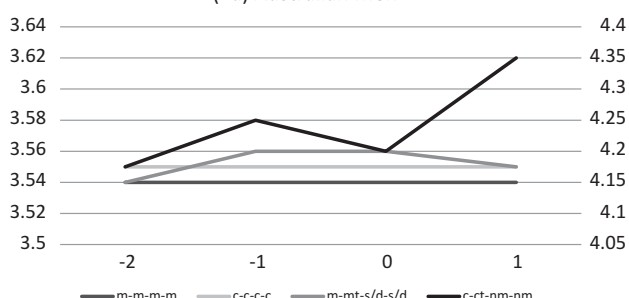

(1c) Australian Women

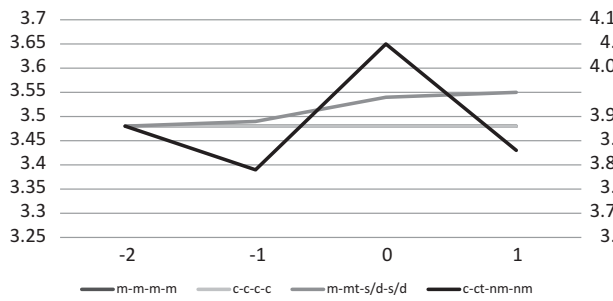

(1b) Swiss Men

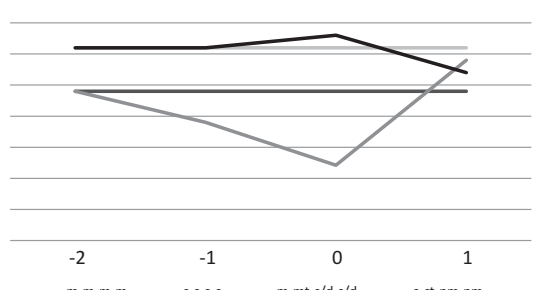

(1d) Swiss Women

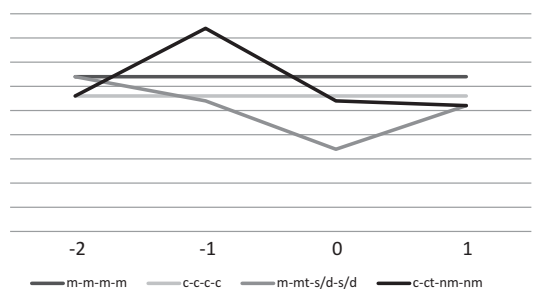

Fig. 3.1 Graphs 1a-1d, relationship dissolution and self-rated health

\section{Negative Feelings}

Our second outcome was the frequency of negative feelings, with results shown in Fig. 3.2. In the year prior to separation from marriage, there was an increase in negative feelings for all groups. Among Swiss men and Australian women this increase is still significant the year of and the year after separation. For Swiss women, these effects are significant in the lagged effect for married-transition. For Swiss men (Fig. 3.2, Graph 2b) we found that separation from cohabitation increased negative feelings, both before, during and after separation. There were no significant associations for Swiss women. Both Australian men and women were significantly more likely to have negative feelings when their cohabiting relationships ended. In sum, there is evidence that separation from both marriage and cohabitation increase the frequency of negative feelings, but separation from marriage had a stronger effect. This is similar in Switzerland and Australia.

\section{Positive Feelings}

In Fig. 3.3, we present the results of the models in the last columns of Appendix Table A.1, assessing the relationship between relationship dissolution and frequency of positive feelings. With the exception of the Swiss women, we find a decrease in the frequency of positive feelings following separation from marriage for all groups, starting the year before separation, and for Swiss men and Australian women continuing through separation and the year following the event. Whereas the pattern displayed in the Figure for Swiss women (Fig. 3.3, Graph 3d) is comparable to that 


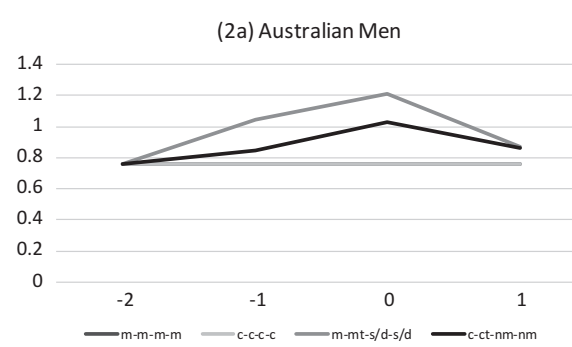

(2c) Australian Women

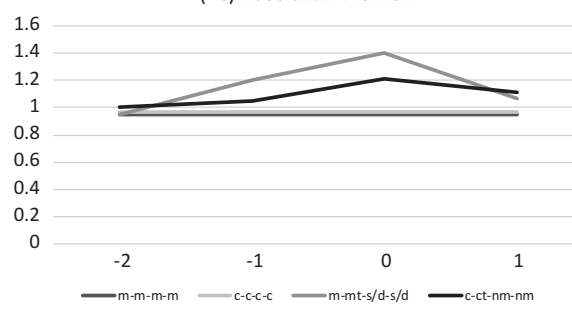

(2b) Swiss Men

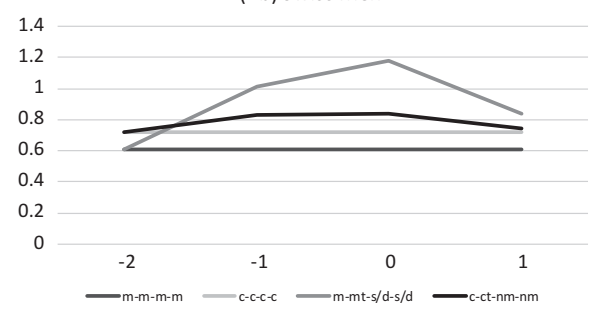

(2d) Swiss Women

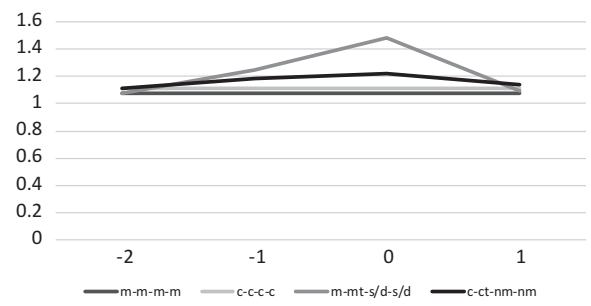

Fig. 3.2 Graphs 2a-2d, relationship dissolution and frequency of negative feelings

(3a) Australian Men

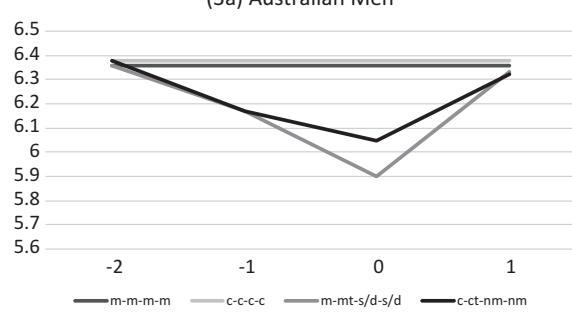

(3c) Australian Women

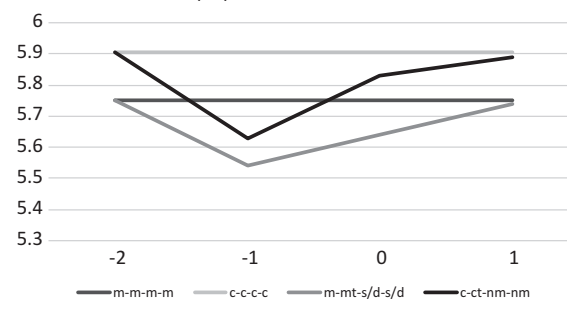

(3b) Swiss Men

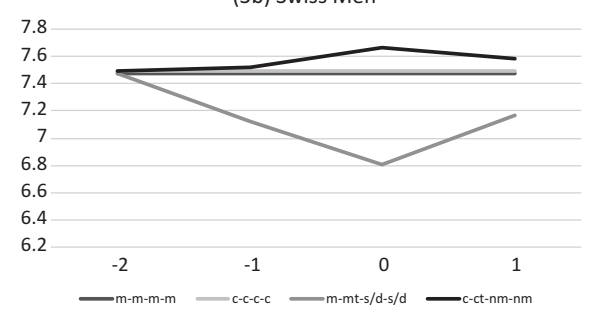

(3d) Swiss Women

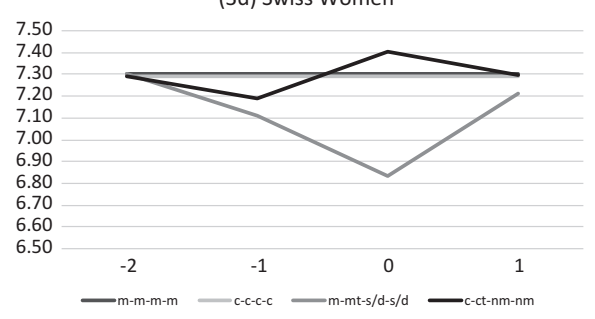

Fig. 3.3 Graphs 3a-3d relationship dissolution and frequency of positive feelings

for the Swiss men (Fig. 3.3, Graph 3b), the coefficients did not reach significance in this group. For the Australian men and women we also found a decrease in positive feelings the year before separation from cohabitation. For Australian men this persisted to the year of separation but disappeared the year after. So we find only for Australia an effect of separation from cohabitation on positive feelings, with comparable effects in Switzerland and Australia of separation from marriage. 


\section{Conclusion}

In this chapter we wanted to further develop our understanding of the differences in the nature and circumstances of marriage and cohabitation by examining the health consequences or relationship dissolution. It is extensively documented that marriage breakdown negatively impacts on health and wellbeing (Umberson et al. 2010), but far less is known about relationship dissolution from cohabitation and whether and to what extent that differs from marital separation. Overall, our results suggest that relationship dissolution was associated with poorer health and wellbeing. However, the balance of evidence indicates that separation from marriage has greater consequences for health and wellbeing than from cohabitation. This is consistent with some prior research (Blekesaune 2008; Hewitt and Baxter 2015). This is also consistent with our expectations, based on the broader research literature comparing and contrasting marriage and cohabitation that finds overall cohabitors (on average) tend to have fewer legal, moral, and structural ties in their relationships, which we argued would likely reduce the health impacts of relationship dissolution for them. We also found that the patterns of associations were similar for Australia and Switzerland.

Our results also suggest differences in the importance of relationship status and relationship transitions for different health outcomes. Where self-reported general health shows the fewest significant associations, there were large and often significant changes in the frequency of negative and positive feelings. This might suggest relationships may be more important for mental well-being rather than physical health. It also indicates that examining multiple dimensions of health and wellbeing provides a more nuanced understanding of how intimate relationships are associated with health and wellbeing (Bierman et al. 2006).

There are a few notable limitations to our study. First, while the health measures available for comparison between HILDA and SHP had some similarities they were not directly comparable. Even if the measures had been identical we could not be sure that the Australian population would have understood the questions in the same way as the Swiss population. Therefore, any conclusions about the comparisons between the two countries need to take that into account. Secondly, we examine transitions from marriage or cohabitation over time, in some cases the numbers and proportions of people transitioning were small. In addition, those whose relationships breakdown have higher rates of attrition than those whose remain intact. These two factors increase the standard error and therefore increase the risk of finding non-significant results, making our results somewhat conservative.

We examined two countries, Australia and Switzerland that contrast in their family and health policy context and relationship formation and dissolution patterns (de Vaus 2004; Heuveline and Timberlake 2005; Shi 1997). Overall, our results suggest that relationship dissolution had similar associations with health in each country. There has been a generalised concern in most developed nations that the rise of cohabitation as an alternative or prelude to marriage, and the relationship instability of cohabitation, may have negative consequences for a range of life outcomes including health (Musick and Bumpass 2012). Our finding that the dissolution of cohabiting relationships were less harmful to health than marriage dissolution contributes to a growing body of evidence that cohabitation as an alternative relationship does not always compare less favourably with marriage. 


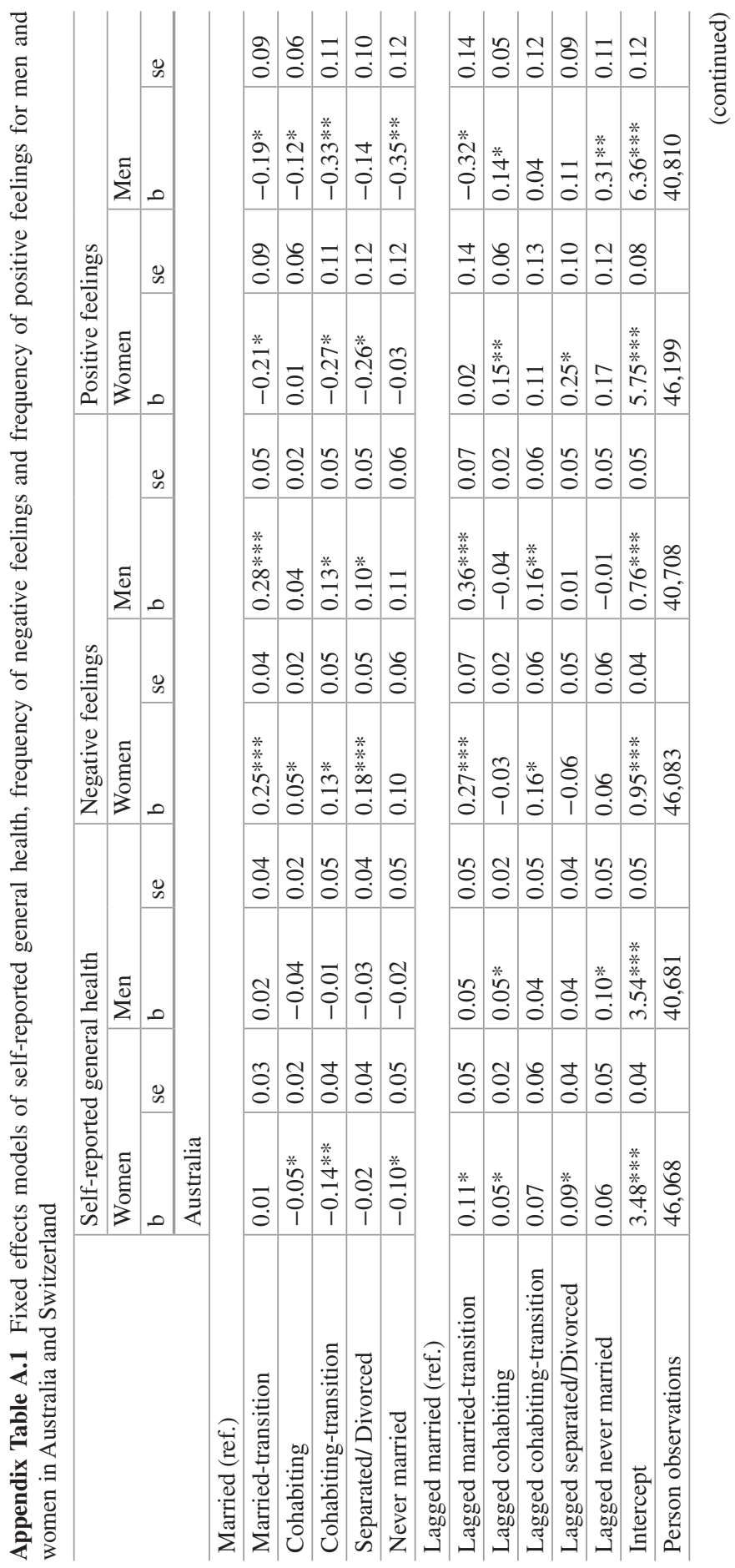




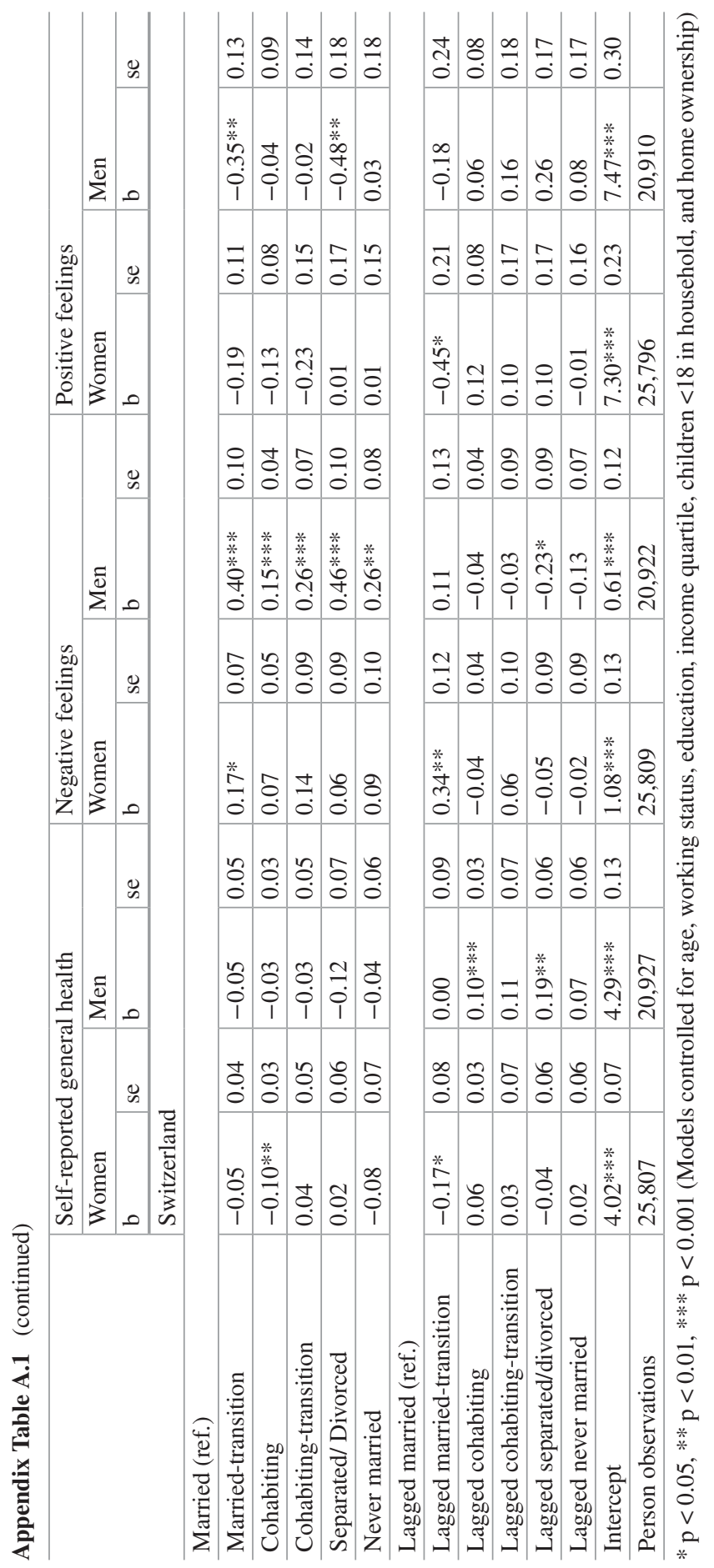




\section{References}

Aassve, A., Betti, G., Mazzuco, S., \& Menacarini, L. (2007). Marital disruption and economic well being. Journal of the Royal Statistical Society: Series A, 170, 781-799.

Amato, P. R. (2000). The consequences of divorce for adults and children. Journal of Marriage and the Family, 62(4), 1269-1287.

Bianchi, S. M., Subaiya, L., \& Kahn, J. R. (1999). The gender gap in the economic well-being of nonresident fathers and custodial mothers. Demography, 36(2), 195-203.

Bierman, A., Fazio, E. M., \& Milkie, M. (2006). A multifaceted approach to the mental health advantage of the married: Assessing how explanations vary by outcome measure and unmarried group. Journal of Family Issues, 27(4), 554-582.

Blekesaune, M. (2008). Partnership transitions and mental distress. Journal of Marriage and Family, 72, 705-725.

Brown, S. L. (2003). Relationship quality dynamics of cohabiting unions. Journal of Family Issues, 24(5), 583-601.

Burstrom, B., \& Fredlund, P. (2001). Self rated health: Is it as good a predictor of subsequent mortality among adults in lower as well as in higher social classes? Journal of Epidemiology and Community Health, 55, 836-840. https://doi.org/10.1136/jech.55.11.836.

Cherlin, A. J. (2009). The marriage-go-round. The state of marriage and family in America today. New York: Knopf.

Gove, W. R., \& Shin, H.-C. (1989). The psychological well-being of divorced and widowed men and women: An empirical analysis. Journal of Family Issues, 10(1), 122-144.

Heuveline, P., \& Timberlake, J. (2005). The Role of cohabitation in family formation: The United States in comparative perspective. Journal of Marriage and the Family, 66(5), 1214-1230.

Hewitt, B., \& Baxter, J. (2015). Chapter 5: Relationship dissolution. In G. Heard \& D. Arunachalam (Eds.), Family formation in 21 st century Australia (pp. 77-99). Dordrecht: Springer.

Hewitt, B., England, P., Baxter, J., \& Shafer, E. F. (2010). Education and unintended pregnancies in Australia: Do differences in relationship status and age at birth explain the gradient? Population Review, 49(1), 36-52.

Hewitt, B., Turrell, G., \& Giskes, K. (2011). Marital loss, mental health and the role of perceived social support: Findings from six waves of an Australian population based panel study. Journal of Epidemiology and Community Health, 66(4), 308-314. https://doi.org/10.1136/ jech.2009.104893.

Hiekel, N., Liefbroer, A. C., \& Poortman, A.-R. (2014). Income pooling strategies among cohabiting and married couples: A comparative perspective. Demographic Research, 30(55), 1527-1560. https://doi.org/10.4054/DemRes.2014.30.55.

Horowitz, A., \& White, H. R. (1998). The relationship of cohabitation and mental health: A study of a young adult cohort. Journal of Marriage and Family, 60(2), 505-514.

Hughes, M. E., \& Waite, L. J. (2009). Marital biography and health at mid-life. Journal of Health and Social Behavior, 50(3), 344-358.

Johnson, D. R., \& Wu, J. (2002). An empirical test of crisis, social selection and role explanations of the relationship between marital disruption and psychological distress: A pooled time-series analysis of four-wave panel data. Journal of Marriage and Family, 64, 211-224.

Kalmijn, M., \& Bernasco, W. (2001). Joint and separated lifestyles in couple relationships. Journal of Marriage and the Family, 63, 639-654.

Kalmijn, M., \& Broese van Groenou, M. (2005). Differential effects of divorce on social integration. Journal of Social and Personal Relationships, 22(4), 455-476.

Kalmijn, M., Loeve, A., \& Manting, D. (2007). Income dynamics in couples and the dissolution of marriage and cohabitation. Demography, 44(1), 159-179.

Kiernan, K. E. (2002). Cohabitation in Western Europe: Trends, issues, and implications. In A. Booth \& A. C. Crouter (Eds.), Just living together: Implications of cohabitation on families, children, and social policy. Mahwah: Erlbaum.

Luhmann, M., Hofmann, W., Eid, M., \& Lucas, R. E. (2012). Subjective well-being and adaptation to life events: A meta-analysis. Journal of Personality and Social Psychology, 102(3), 592-615. 
Lund, R., Due, P., Modvig, J., Holstein, B. E., Damsgaard, M. T., \& Andersen, P. K. (2002). Cohabitation and marital status as predictors of mortality an eight year follow-up study. Social Science \& Medicine, 55, 673-679.

Martikainen, P., Aromaa, A., Heliovaara, M., Klaukka, T., Knekt, P., Maatela, J., et al. (1999). Reliability of perceived health by sex and age. Social Science \& Medicine, 48(8), 1117-1122.

Monden, C. W. S., \& Uunk, W. (2013). For better and for worse: The relationship between union dissolution and self-assessed health in European panel data. European Journal of Population/ Revue Europeenne de Demographie, 29, 103-125.

Mulder, C. H., \& Wagner, M. (2001). The connections between family formation and first-time home ownership in the context of West Germany and the Netherlands. European Journal of Population/Revue Europeenne de Demographie, 17(2), 137-164.

Musick, K., \& Bumpass, L. L. (2012). Reexamining the case for marriage: Union formation and changes in well-being. Journal of Marriage and Family, 74(2), 1-18.

Nock, S. L. (1995). A comparison of marriage and cohabiting relationship. Journal of Family Issues, 16(1), 53-76.

Seltzer, J. A. (2000). Families formed outside of marriage. Journal of Marriage and the Family, $62,1247-1268$.

Shaw, B., \& Liang, J. (2012). Chapter 7: Growth models with multilevel regression. In J. T. Newsom, R. N. Jones, \& S. M. Hofer (Eds.), Longitudinal data analysis: A practical guide for research in aging, health and social sciences. New York: Routledge.

Shi, L. (1997). Health care spending, delivery, and outcome in developed countries: A crossNational Comparison. American Journal of Medical Quality, 12(2), 83-93.

Soons, J., \& Kalmijn, M. (2009). Is marriage more than cohabitation? Well-being differences in 30 European countries. Journal of Marriage and Family, 71, 1141-1157.

Umberson, D., Crosnoe, R., \& Reczek, C. (2010). Social relationships and health behaviour across the life course. Annual Review of Sociology, 36, 139-157. https://doi.org/10.1146/ annurev-soc-070308-120011.

de Vaus, D. A. (2004). Diversity and change in Australian families: Statistical profiles. Melbourne: AIFS.

Wiik, K. A., Keizer, R., \& Lappegard, T. (2012). Relationship quality in marital and cohabtiing unions across Europe. Journal of Marriage and Family, 74, 389-398.

Williams, K., \& Umberson, D. (2004). Marital status, marital transitions, and health: A gendered life course perspective. Journal of Health \& Social Behavior, 45(1), 81-98.

Wu, Z., Penning, M. J., Pollard, M. S., \& Hart, R. (2003). "In sickness and in health" : Does cohabitation count? Journal of Family Issues, 24(6), 811-838.

Xie, Y., Raymo, J. M., Goyette, K., \& Thornton, A. (2003). Economic potential and entry into marriage and cohabitation. Demography, 40(2), 351-367.

Open Access This chapter is licensed under the terms of the Creative Commons Attribution 4.0 International License (http://creativecommons.org/licenses/by/4.0/), which permits use, sharing, adaptation, distribution and reproduction in any medium or format, as long as you give appropriate credit to the original author(s) and the source, provide a link to the Creative Commons license and indicate if changes were made.

The images or other third party material in this chapter are included in the chapter's Creative Commons license, unless indicated otherwise in a credit line to the material. If material is not included in the chapter's Creative Commons license and your intended use is not permitted by statutory regulation or exceeds the permitted use, you will need to obtain permission directly from the copyright holder.

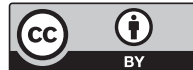

